\title{
Los derechos sexuales y reproductivos de las mujeres en México. La Interrupción legal del embarazo
}

\author{
The sexual and reproductive rights of women in Mexico. The legal \\ termination of pregnancy
}

Yunitzilim RodRíguez PedrazA ${ }^{1}$

$:^{\circ}$ IUS Comiliãlis / Año 4, Número 7 / enero - junio 2021 / pp. 91-118 / ISSN: 2594-1356 Recepción: 14 de abril de 2020 / Aceptación: 15 de septiembre de 2020

\section{(c) $(1)(9)$}

Esta obra está bajo licencia Creative Commons

Attribution-NonCommercial-ShareAlike $\quad 4.0$

International (CC BY-NC-SA 4.0)

Resumen: Una de las exigencias de las mujeres en México se centra en la defensa del derecho a decidir sobre sus proyectos de vida y específicamente sobre sus cuerpos, enfrentando un sistema patriarcal y misógino que las condena a la maternidad y todo lo que esta conlleva, sin considerar a los derechos sexuales y reproductivos como parte del derecho humano a la salud, el derecho a la dignidad y al libre desarrollo de la personalidad, visibilizando la opacidad del Estado en la protección de sus vidas y su seguridad, lo que conlleva violencia institucional al criminalizar el derecho a decidir sobre sus cuerpos.

Palabras clave: aborto; maternidad; derecho a la salud; violencia de género por agravio equiparado; violencia institucional.

Abstract: One of the demands of women in Mexico focuses on defending the right to decide on their life projects and specifically on their bodies, facing a patriarchal and misogynistic system that condemns them to motherhood and all that it entails, without considering sexual and reproductive rights as part of the human right to health, the right to dignity and the free development of personality, making visible the opacity of the state in the protection of their lives and security, which entails institutional violence.

Key words: abortion; maternity; right to health; gender violence due to equal injury; institutional violence.

${ }^{1}$ Doctora en Derecho, profesora Investigadora de Tiempo Completo, Departamento de Ciencias Jurídicas de la División de Ciencias Sociales y Económico Administrativas, México. 


\section{INTRODUCCIÓN}

La reforma constitucional de 2011 en materia de derechos humanos en México fue el inicio de una nueva era en materia jurídica; algunos paradigmas se rediseñaban y el Estado mexicano -al menos legalmente y después de varios años de haber suscrito instrumentos internacionales que ya eran vinculatorios- aceptaba su responsabilidad de promover, respetar, proteger y garantizar los derechos humanos.

Con ese convencimiento quienes se tomaron sus derechos en serio continuaron con el impulso de una serie de acciones, no solo legales, sino también de presión social para exigir al Estado el cumplimiento de sus obligaciones. Entre esos grupos se encuentran quienes defienden los derechos sexuales y reproductivos de las mujeres, específicamente el derecho a la interrupción voluntaria del embarazo, amparadas en el derecho al libre desarrollo de su personalidad y al de decidir sobre sus cuerpos, en la búsqueda de la posibilidad de desarrollar sus proyectos de vida, poder acceder a las mismas oportunidades que los varones y eliminar los obstáculos que por el hecho de haber nacido mujer enfrentan.

Más allá de posturas de tipo biológica, médica, ética, moral, filosófica o religiosa, el análisis debe ser objetivo; por ello, es necesario establecer algunos cuestionamientos y desarrollar un análisis de estos. Si el derecho a la salud está protegido por la Constitución ¿Abarca los derechos sexuales y reproductivos y la interrupción voluntaria del embarazo? ¿Qué compromisos ha suscrito México a nivel internacional en la materia? ¿Cuál es el sentido de las recomendaciones que han emitido los Comités de seguimiento de los instrumentos internacionales que México ha suscrito respecto a los derechos sexuales y reproductivos de las mujeres? ¿Establecer la hipótesis normativa del aborto en el Código Penal implica una violación a los derechos sexuales y reproductivos de las mujeres? ¿Qué criterios ha establecido la Suprema Corte de Justicia de la Nación en beneficio de los derechos sexuales y reproductivos de las mujeres y en específico de su derecho a la interrupción voluntaria del embarazo?

La interrupción del embarazo (ILE) hasta la décimo segunda semana es legal únicamente en dos entidades federativas del país -Ciudad de México² y Oaxaca³.

En el caso de la Ciudad de México, el Código Penal reformado el 26 de abril de 2007 señala en sus artículos 144 al 147: (CPDF)

Artículo 144. Aborto es la interrupción del embarazo después de la décima segunda semana de gestación.

\footnotetext{
${ }^{2}$ El 26 de abril de 2007 fue publicada en la Gaceta Oficial del Distrito Federal el decreto de reformas a los artículos 144 a 147 del Código Penal del Distrito Federal, y de reforma y adiciones de la Ley de Salud para el Distrito Federal.

${ }^{3}$ A partir de la aprobación mayoritaria del Congreso del estado de Oaxaca el 25 de septiembre de 2019. https://aristeguinoticias.com/2509/mexico/es-legal-oaxaca-aprueba-despenalizacion-del-aborto/
} 
Para los efectos de este Código, el embarazo es la parte del proceso de la reproducción humana que comienza con la implantación del embrión en el endometrio.

Artículo 145. Se impondrá de tres a seis meses de prisión o de 100 a 300 días de trabajo a favor de la comunidad, a la mujer que voluntariamente practique su aborto o consienta en que otro la haga abortar, después de las doce semanas de embarazo. En este caso, el delito de aborto sólo se sancionará cuando se haya consumado.

Al que hiciere abortar a una mujer, con el consentimiento de ésta, se le impondrá de uno a tres años de prisión.

Artículo 146. Aborto forzado es la interrupción del embarazo, en cualquier momento, sin el consentimiento de la mujer embarazada.

Para efectos de este artículo, al que hiciere abortar a una mujer por cualquier medio sin su consentimiento, se le impondrá de cinco a ocho años de prisión. Si mediare violencia física o moral, se impondrá de ocho a diez años de prisión.

Artículo 147. Si el aborto o aborto forzado lo causare un médico cirujano, comadrón o partera, enfermero o practicante, además de las sanciones que le correspondan conforme a este capítulo, se le suspenderá en el ejercicio de su profesión u oficio por un tiempo igual al de la pena de prisión impuesta.

En el caso de Oaxaca, el texto legal del Código Penal reformado mediante decreto número 806, aprobado por la LXIV Legislatura del Estado el 25 de septiembre del 2019 y publicado en el Periódico Oficial Extra del 24 de octubre del 2019, quedó de la siguiente manera: (CPOAX)

Artículo 312.- Aborto es la interrupción del embarazo después de la décima segunda semana de gestación.

Para los efectos de este Código, el embarazo es la parte del proceso de la reproducción humana que comienza con la implantación del embrión en el endometrio.

Artículo 313.- Aborto forzado es la interrupción del embarazo, en cualquier momento, sin el consentimiento de la mujer embarazada. En este caso, el delito de aborto forzado podrá ser sancionado en grado de tentativa, en los términos dispuestos por el presente Código.

Al que hiciere abortar a una mujer, sin el consentimiento de ésta, se le aplicarán de tres a seis años de prisión, sea cual fuere el medio que empleare. Si además mediare violencia física o moral, se impondrán al infractor de seis a diez años de prisión.

Ello implica que, en esas dos entidades, las mujeres pueden interrumpir su embarazo dentro del periodo establecido sin el temor de ser objeto de una sanción penal mientras que en el resto de las entidades no. Ante esa distinción: ¿Existe violencia de género por agravio equiparado para las 30 entidades restantes según lo señalado por la Ley General de Acceso a las Mujeres a una vida libre de Violencia y su reglamento? ¿Es adecuado que las mujeres de las demás entidades federativas puedan ejercer menos derechos? ¿Existen ciudadanas de primera -quienes si pueden acceder a efectuarse una ILE en su entidad sin ser criminalizadas- y de segunda -quienes no-? 


\section{DIFERENCIA ENTRE VIDA HUMANA Y PERSONA HUMANA}

El desarrollo de esta discusión no se basa en determinar la diferencia entre una vida humana y una persona humana, pues ese extremo ha sido superado -aun cuando exista una cerrazón para aceptarlo- desde el año 2012, con la sentencia emitida por unanimidad por la Corte Interamericana de Derechos Humanos en el caso Artavia Murillo y otros ("Fecundación In Vitro") Vs. Costa Rica (CIDH) que se puede resumir de la siguiente manera (CELS, págs. 9-10):

"La Corte IDH dijo en esa oportunidad que una 'interpretación histórica y sistemática de los antecedentes existentes en el Sistema Interamericano, confirma que no es procedente otorgar el estatus de persona al embrión'. Entendió que el embrión no tiene capacidad autónoma de desarrollarse como individuo y por ende, no puede reconocerse la existencia de un sujeto de derechos. Por el contrario, el objeto directo de protección del artículo 4.1 de la $\mathrm{CADH}$ es la persona gestante.

En el mismo caso, la Corte IDH analizó las normas del sistema universal de derechos humanos que consagran el derecho a la vida para concluir que no incluyen al embrión como persona a ser protegida. La Corte señaló que la expresión "ser humano", utilizada en el artículo 1 de la Declaración Universal de Derechos Humanos (DUDH) no fue entendida en el sentido de incluir al no nacido. Indicó, también, que los trabajos preparatorios del artículo 6.1 del Pacto Internacional de Derechos Civiles y Políticos (PIDCP) -"El derecho a la vida es inherente a la persona humana. Este derecho estará protegido por la ley. Nadie podrá ser privado de la vida arbitrariamente”- señalan que los Estados no pretendían tratar al no nacido como persona y otorgarle el mismo nivel de protección. Para la Corte IDH, las decisiones del Comité de Derechos Humanos permiten afirmar que del PIDCP no se deriva una protección absoluta de la vida prenatal o del embrión. Por último, la Corte IDH afirmó que los artículos 1 y 6.1 de la Convención sobre los Derechos del Niño "no se refieren de manera explícita a la protección del no nacido. El Preámbulo hace referencia a la necesidad de brindar 'protección y cuidado especiales [...] antes [...] del nacimiento'. Sin embargo, los trabajos preparatorios indican que esta frase no tuvo la intención de hacer extensivo al no nacido lo dispuesto en la Convención, en especial el derecho a la vida”.

Por tanto, se concluye que la persona humana es el sujeto de protección de las convenciones, pactos, tratados, constituciones y leyes, o por lo menos deberían ser, puesto que no se le deben ni pueden reconocer mayores derechos a un producto o ser vivo que a una persona o ser humano. 


\section{LOS DERECHOS SEXUALES Y REPRODUCTIVOS COMO DERECHOS HUMANOS}

Para la Organización Mundial de la Salud, el goce del grado máximo de salud que se pueda lograr es uno de los derechos fundamentales de todo ser humano sin distinción de raza, religión, ideología política o condición económica o social ${ }^{4}$. El derecho a la salud también hace referencia al derecho que debe tener toda persona a ser dueña de su salud y su cuerpo, y a tener acceso a información y a servicios de salud sexual y reproductiva, sin ser objeto de violencia y discriminación. (Adhanom Ghebreyesus, 2017)

El derecho a la salud no solo es ausencia de enfermedades, implica el derecho de toda persona a ser dueña de su salud y su cuerpo, de ahí se deriva el derecho a la integridad física, psíquica y moral: la libre determinación de su personalidad, a decidir sobre su cuerpo, a la autonomía, dignidad, a una vida libre de violencia, ${ }^{5}$ entre otros derechos; con esto se reafirma la interdependencia de los derechos humanos, puesto que si no se garantiza el derecho a la salud en toda su extensión, se imposibilita el goce y disfrute de muchos más.

Tener acceso a información, servicios de salud sexual y reproductiva y sin ser objeto de violencia y discriminación, conlleva no solo la obligación del Estado de brindar educación integral de la sexualidad y tener disponibles métodos anticonceptivos; sino además, proporcionar los servicios que trae aparejado el ejercicio de ese derecho como lo sería el aborto, enfatizando que debe hacerse sin discriminación, cuestión que viven las mujeres que deciden interrumpir su embarazo ante políticas públicas elaboradas desde el patriarcado y la misoginia que las condenan a la maternidad y las juzgan ante decisiones contrarias a los estereotipos imponiéndoles sanciones que implican privación de su libertad personal.

El derecho a la salud no es solo no tener enfermedades o estar saludable, sino el derecho a una serie de servicios, estructuras, bienes y condiciones que promuevan y protejan el más alto estándar de salud posible. El derecho a la salud individual, de un colectivo, comunidad o país ha de ser protegido por las autoridades locales, comunitarias o nacionales y el Estado ha de situarse como responsable último en la garantía de ese derecho. (Caba \& Vázquez, pág. 30)

Los derechos sexuales y reproductivos son derechos humanos y representan una obligación del estado. Lograr emitir ese enunciado hoy es una realidad a pesar de las reticencias, gracias a avances significativos que se han tenido en conferencias mundiales donde ha quedado claro que no se puede seguir evadiendo una problemática grave que afecta a las mujeres y que, sin duda, representa una más de las manifestaciones claras y directas de la violencia de género en su contra.

\footnotetext{
${ }^{4}$ Preámbulo de la Constitución de la Organización Mundial de la Salud, que fue adoptada por la Conferencia Sanitaria Internacional, celebrada en Nueva York del 19 de junio al 22 de julio de 1946, firmada el 22 de julio de 1946 por los representantes de 61 Estados (Official Records of the World Health Organization, $\mathrm{N}^{\circ} 2$, p. 100), y entró en vigor el 7 de abril de 1948. La definición no ha sido modificada desde 1948.

${ }_{5}^{5}$ Esa es la razón primordial por la que la violencia contra las mujeres es un tema de salud pública. 
Acerca del contenido y alcance del derecho fundamental a la salud, la Primera Sala de la Suprema Corte de Justicia de la Nación, ha señalado que:

“...en congruencia con lo establecido por el Comité de Derechos Económicos, Sociales y Culturales de las Naciones Unidas, el derecho a la salud debe entenderse como una garantía fundamental e indispensable para el ejercicio de los demás derechos humanos y no sólo como el derecho a estar sano. Así, el derecho a la salud entraña libertades y derechos, entre las primeras, la relativa a controlar la salud y el cuerpo, con inclusión de la libertad sexual y genésica, y el derecho a no padecer injerencias, torturas, tratamientos o experimentos médicos no consensuales; y entre los derechos, el relativo a un sistema de protección de la salud que brinde a las personas oportunidades iguales para disfrutar del más alto nivel posible de salud. [...]de ahí que el derecho a la salud debe entenderse como un derecho al disfrute de toda una gama de facilidades, bienes, servicios y condiciones necesarios para alcanzar el más alto nivel posible de salud". ${ }^{6}$

El capítulo VII del Informe de la Conferencia Internacional sobre Población y Desarrollo celebrada en el Cairo en el año 1994 aprobado por consenso, se titula Derechos reproductivos y salud reproductiva; en su párrafo 7.2 menciona lo siguiente:

"La salud reproductiva es un estado general de bienestar físico, mental y social, y no de mera ausencia de enfermedades o dolencias, en todos los aspectos relacionados con el sistema reproductivo y sus funciones y procesos. En consecuencia, la salud reproductiva entraña la capacidad de disfrutar de una vida sexual satisfactoria y sin riesgos y de procrear, y la libertad para decidir hacerlo o no hacerlo, cuándo y con qué frecuencia. Esta última condición lleva implícito el derecho del hombre y la mujer a obtener información y de planificación de la familia de su elección, así como a otros métodos para la regulación de la fecundidad que no estén legalmente prohibidos, y acceso a métodos seguros, eficaces, asequibles y aceptables, el derecho a recibir servicios adecuados de atención de la salud que permitan los embarazos y los partos sin riesgos y den a las parejas las máximas posibilidades de tener hijos sanos. En consonancia con esta definición de salud reproductiva, la atención de la salud reproductiva se define como el conjunto de métodos, técnicas y servicios que contribuyen a la salud y al bienestar reproductivo al evitar y resolver los problemas relacionados con la salud reproductiva. Incluye también la salud sexual, cuyo objetivo es el desarrollo de la vida y de las relaciones personales y no meramente el asesoramiento y la atención en materia de reproducción y de enfermedades de transmisión sexual” (pág. 37)

A su vez, en el informe derivado de la Cuarta Conferencia Mundial sobre la Mujer celebrada en Beijing, en su párrafo 96, por consenso planteó que:

\footnotetext{
${ }^{6}$ Tesis aislada LXV/2008 de la Primera Sala de la Suprema Corte de Justicia de la Nación, visible en la página 457 del Tomo XXVIII (julio de 2008) del Semanario Judicial de la Federación y su Gaceta, de rubro: "DERECHO A LA SALUD. SU REGULACIÓN EN EL ARTÍCULO $4^{\circ}$. DE LA CONSTITUCIÓN POLÍTICA DE LOS ESTADOS UNIDOS MEXICANOS Y SU COMPLEMENTARIEDAD CON LOS TRATADOS INTERNACIONALES EN MATERIA DE DERECHOS HUMANOS.”
} 
"Los derechos humanos de la mujer incluyen su derecho a tener control sobre las cuestiones relativas a su sexualidad, incluida su salud sexual y reproductiva, y decidir libremente respecto de esas cuestiones, sin verse sujeta a la coerción, la discriminación y la violencia. Las relaciones igualitarias ente la mujer y el hombre respecto de la integridad de la persona, exigen el respeto y el consentimiento recíprocos y la voluntad de asumir conjuntamente la responsabilidad de las consecuencias del comportamiento sexual.” (ONU, 1995, pág. 38)

Imponer la maternidad ha sido una de las principales consignas del sistema patriarcal que ha dominado históricamente y que ha impuesto el orden jurídico pues condena a la mujer que intenta decidir sobre su proyecto de vida, su cuerpo y su futuro, asignándole más valor a un producto que a la persona humana.

Esa imposición ha costado muchas vidas. Los abortos no seguros causan la muerte de unas 47.000 mujeres cada año y otros cinco millones sufren alguna forma de discapacidad temporal o permanente. La mortalidad materna viola los derechos a la vida, la salud, la igualdad y la no discriminación. Las cuestiones relacionadas con el acceso a un aborto seguro y legal son la esencia del derecho fundamental de la mujer a la igualdad, privacidad y salud física y mental, y estas son condiciones previas para el disfrute de otros derechos y libertades. (ACNUDH, 2018)

Pareciera que en el mundo existen niveles o calidad diversa de mujeres: las de primera que son las que viven en países desarrollados; las de segunda que son quienes nacieron en un país en vías de desarrollo y las de tercera, a quienes sin importar el país o continente donde viven ni el grado de desarrollo de éste, se les imponen tradiciones y costumbres violatorias a sus derechos humanos.

En lo que respecta al aborto, mientras que en la mayoría de los países europeos la interrupción de embarazo es legal con independencia del motivo, Latinoamérica, junto con África, impone la mayor cantidad de restricciones al respecto. La situación actual sobre la legalización del aborto en el mundo ofrece un panorama que puede resumirse en que es permitido y accesible en casi todo el mundo desarrollado y que, en contraste, las leyes son restrictivas y el aborto seguro muy poco accesible en la mayor parte de los países menos desarrollados. En América Latina, los únicos países que tienen leyes ampliamente permisivas y aborto seguro accesible son Cuba y ahora Uruguay, además del Distrito Federal de México. (Faundes, 2015, pág. 425) Habría que agregar a la lista al Estado de Oaxaca, que desde el mes de octubre de 2019, publicó en su Periódico Oficial las reformas Código Penal en donde sanciona al aborto cuando se efectúa después de la décimo segunda semana de gestación. (DEC806) 


\section{LOS COMPROMISOS INTERNACIONALES DEL ESTADO MEXICANO FRENTE A LA INTERRUPCIÓN LEGAL DEL EMBARAZO}

En los últimos años el Estado mexicano ha incorporado a su marco normativo nacional, diversas disposiciones encaminadas a garantizar a las mujeres el derecho a una vida sin discriminación y violencia, establecidas como obligaciones en diversos instrumentos internacionales tales como; la Convención para la Eliminación de todas las Formas de Discriminación contra la Mujer $^{7}(\mathrm{CEDAW})^{8}$ y la convención Interamericana para Prevenir, Sancionar y Erradicar la Violencia contra la Mujer, conocida como Convención Belem do Pará, en los que se establecieron compromisos claros para eliminar los obstáculos de todo tipo que impiden a las mujeres el desarrollo de su proyecto de vida, así como establecer acciones afirmativas, por tanto, al ser los derechos sexuales y reproductivos un derecho humano, el Estado tiene la obligación de garantizarlos y protegerlos.

En lo que respecta a la Convención Interamericana para Prevenir, Sancionar y Erradicar la Violencia Contra la Mujer (Belém do Pará), ratificada por México el doce de noviembre de mil novecientos noventa y ocho, se afirmó que la violencia contra la mujer constituye una violación de los derechos humanos y las libertades fundamentales y limita total o parcialmente a la mujer su reconocimiento, goce y ejercicio (SCJN, 2017, pág. 52). Los Estados que suscriben dicho pacto internacional se obligan a condenar toda forma de violencia contra la mujer y convienen en adoptar, mediante los instrumentos apropiados, políticas orientadas a prevenir, sancionar y erradicar dicha violencia (artículo $7^{\circ}$ ); asimismo, se comprometen a desarrollar acciones, como (SCJN, 2017, pág. 53):

- Abstenerse de ejercer cualquier práctica de violencia contra la mujer y velar por que las autoridades y funcionarios se comporten de conformidad a dicha obligación.

- Actuar con diligencia para prevenir, investigar y sancionar la violencia contra la mujer.

- Tomar todas las medidas apropiadas, incluyendo medidas de legislativas, para modificar o abolir leyes y reglamentos vigentes, o para modificar prácticas jurídicas o consuetudinarias que respalden la persistencia o la tolerancia de la violencia contra la mujer.

La suscripción y adherencia a instrumentos internacionales no es sólo un acto de diplomacia ni de buenas intenciones. Implica para el Estado una obligación de apegarse a los principios y contenido y para las personas que se encuentran en la circunscripción territorial del Estado parte, un elemento de protección de sus derechos y sobre todo, para exigir su cumplimiento.

La Oficina del Alto Comisionado de las Naciones Unidas ha establecido que:

\footnotetext{
${ }^{7}$ Vinculación de México a la CEDAW el 23 de marzo de 1980. INMUJERES. Disponible en http://cedoc.inmujeres.gob.mx/documentos_download/100039.pdf.

${ }^{8}$ Siglas en Inglés.
} 
"Los Estados de todo el mundo deben actuar ahora para despenalizar el aborto y hacer todo lo posible para garantizar que las mujeres y las niñas tengan derecho a tomar sus propias decisiones sobre el embarazo" (ACNUDH). Ese señalamiento está basado en el convencimiento de las implicaciones negativas que tiene en las mujeres el imponerles la maternidad, bajo la consciencia que es un estereotipo en perjuicio del desarrollo integral de las mismas.

Respecto a la discriminación, la Convención sobre la eliminación de todas las formas de discriminación contra la mujer (CEDAW) establece:

Artículo 1. A los efectos de la presente Convención, la expresión "discriminación contra la mujer" denotará toda distinción, exclusión o restricción basada en el sexo que tenga por objeto o resultado menoscabar o anular el reconocimiento, goce o ejercicio por la mujer, independientemente de su estado civil, sobre la base de la igualdad del hombre y la mujer, de los derechos humanos y las libertades fundamentales en las esferas política, económica, social, cultural y civil o en cualquier otra esfera.

Dicha Convención tiene un Comité quien ha emitido observaciones y recomendaciones específicas en cuanto al acceso a la Interrupción Voluntaria del Embarazo:

En 2018, el Comité sesionó y con base en la recomendación número 42, en consonancia con su recomendación general núm. 24 (1999) sobre la mujer y la salud, el Comité recomienda al Estado que ponga mayor empeño en acelerar la armonización de las leyes y los protocolos federales y estatales sobre el aborto para garantizar el acceso al aborto legal y, aunque no haya sido legalizado, a los servicios de atención posterior al aborto (ONUMUJERES).

Por su parte, el Comité de Derechos Humanos de la Organización de las Naciones Unidas, emitió la Observación General núm. 36 sobre el artículo 6 del Pacto Internacional de Derechos Civiles y Políticos, relativo al derecho a la vida y señala que (OHCHR, pág. 2):

"Los Estados partes no deben regular el embarazo ni el aborto de manera contraria a su deber de velar por que las mujeres no tengan que recurrir a abortos peligrosos. [Por ejemplo, no deben adoptar medidas como penalizar los embarazos de las mujeres solteras, ni aplicar sanciones penales a las mujeres que se someten a un aborto o a los médicos que las asisten para hacerlo, cuando se prevea que la adopción de esas medidas va a suponer un aumento significativo de los abortos peligrosos.] Los Estados partes tampoco deben establecer requisitos excesivamente onerosos o humillantes para las mujeres que deseen someterse a un aborto. La obligación de proteger la vida de las mujeres contra los riesgos para la salud relacionados con los abortos peligrosos exige que los Estados partes garanticen a mujeres y hombres, y en particular a los adolescentes, acceso a información y educación sobre las opciones reproductivas y a toda una serie de métodos anticonceptivos. Los 
Estados partes también deben velar por que las mujeres embarazadas tengan acceso a servicios de atención de la salud adecuados, tanto prenatales como con posterioridad al aborto.”

El Comité para la Eliminación de la Discriminación contra la Mujer especifica que "la negativa de un Estado Parte a prever la prestación de determinados servicios de salud reproductiva a la mujer en condiciones legales resulta discriminatoria" (CEDAW, 1999, párr. 11). Establece, además que "las leyes que penalizan ciertas intervenciones médicas que afectan exclusivamente a la mujer y castigan a las mujeres que se someten a dichas intervenciones constituyen un obstáculo para el acceso de las mujeres a la atención de salud” (párr. 14).

Por tanto, no hay duda, el Estado mexicano tiene un compromiso internacional de armonizar su legislación con la debida perspectiva de género para garantizar el derecho a las mujeres a decidir sobre sus cuerpos, eliminando los tipos penales que impliquen criminalización y punición, estableciendo los medios y recursos para acompañarlas de manera institucional en el caso que decidan abortar sin importar la causa, para evitar que su vida se ponga en riesgo, puesto que es su vida -la de las mujeres-, la que debe ponderarse.

Esta ponderación resulta que, al quedar claro que no existen derechos establecidos al embrión o producto en gestación y que, en todo caso, no puede dársele mayores derechos a éste que a la persona viva, autónoma, sujeta de derechos, a la que el Estado, se encuentra obligado a garantizar, proteger y respetar sus derechos.

\section{LA NORMATIVA NACIONAL EN LA MATERIA}

A partir de la reforma de 2011 en materia de derechos humanos, el artículo primero reconoce la obligación del Estado de favorecer, brindar y proteger a las personas; garantizando el ejercicio de los derechos humanos previstos en el texto constitucional y en los tratados internacionales de los que es parte, lo que reafirma la intención de afrontar la responsabilidad emitida desde el 8 de diciembre de 1998 cuando México reconoció la competencia contenciosa de la Corte Interamericana de Derechos Humanos (DOF) sobre los casos relativos a la interpretación o aplicación de la Convención Americana sobre Derechos Humanos, lo que establece para las personas un mecanismo internacional para exigir al estado, el cumplimiento de los compromisos pactados.

Por su parte el artículo cuarto de la Constitución Política de los Estados Unidos Mexicanos señala:

Artículo 40. El varón y la mujer son iguales ante la ley. Esta protegerá la organización y el desarrollo de la familia.

Toda persona tiene derecho a decidir de manera libre, responsable e informada sobre el número y el espaciamiento de sus hijos. 
Toda persona tiene derecho a la alimentación nutritiva, suficiente y de calidad. El Estado lo garantizará.

Toda persona tiene derecho a la protección de la salud. La Ley definirá las bases y modalidades para el acceso a los servicios de salud y establecerá la concurrencia de la Federación y las entidades federativas en materia de salubridad general, conforme a lo que dispone la fracción XVI del artículo 73 de esta Constitución...

El derecho a la salud y todas las implicaciones que conlleva -servicios, información, infraestructura, bienes, condiciones, etc.- están garantizados por la Carta Magna y respaldados por los instrumentos internacionales de los que se ha hecho mención en el apartado previo.

Aunado a otros instrumentos normativos como la Ley General de Salud, la Ley General de Educación y la Ley General de Víctimas que señalan algunos apartados específicos en los que se considera la perspectiva de género y la no discriminación como principios fundamentales, existen otros instrumentos que regulan acciones directas en beneficio de las mujeres como la Ley General para la igualdad entre hombres y mujeres y su reglamento, la Ley General de Acceso de las Mujeres a una Vida Libre de Violencia y su reglamento, así como el Reglamento para el funcionamiento del Sistema Nacional para Prevenir, Atender, Sancionar y Erradicar la Violencia contra las Mujeres, los cuáles si bien son herramientas para la defensa de los derechos de las mujeres, no han significado un cambio sustancial en el ejercicio pleno de sus derechos humanos y mucho menos a favor de sus derechos sexuales y reproductivos.

\section{EL ACTUAR DE LA SUPREMA CORTE DE JUSTICIA DE LA NACIÓN FRENTE A LOS DERECHOS SEXUALES Y REPRODUCTIVOS DE LAS MUJERES}

La imposición de la maternidad ha sido una constante, pero también lo ha sido el reclamo social frente a las normas que institucionalizan la discriminación hacia las mujeres. En ese camino, el Poder Judicial de la Federación a través de la Suprema Corte de Justicia de la Nación (SCJN), ha ido marcando una interpretación acorde a la protección de los derechos sexuales y reproductivos, evidenciando la intención del estado, a través de sus instituciones, de perpetuar los estereotipos que criminalizan a quienes deciden acceder a una ILE y a ejercitar el derecho a decidir sobre sus cuerpos y sus proyectos de vida.

En ese sentido, resulta por demás interesante analizar de manera somera, algunos de las principales interpretaciones que, en diversos momentos, la SCJN ha efectuado respecto al tema: 


\section{ACCIÓN DE INCONSTITUCIONALIDAD 146/2007 Y SU ACUMULADA 147/2007, “DESPENALIZACIÓN DEL ABORTO EN EL DF” (SCJN, 2008)}

Mediante decreto publicado el 26 de abril de 2007, expedido por la Asamblea Legislativa del Distrito Federal y promulgado por el jefe de Gobierno del Distrito Federal se aprobó la ley que despenaliza el aborto hasta la semana 12 de gestación, incluyendo mecanismos para la impartición de servicios de salud adecuados.

La reforma consistió en la modificación de artículos diversos del Código Penal del Distrito Federal y de la Ley de Salud del Distrito Federal.

El 24 de mayo de 2007, el presidente de la Comisión Nacional de los Derechos Humanos (CNDH) José Luis Soberanes Fernández y el día 25 de mayo de 2007, el titular de la Procuraduría General de la República (PGR) Eduardo Medina-Mora Icaza, interpusieron acciones de inconstitucionalidad en contra de las reformas.

Ambos solicitaron:

- La inconstitucionalidad de la reforma a los artículos 144, 145, 146 y 147 del Código Penal para el Distrito Federal, que entre otros extremos señalan que el aborto es la interrupción del embarazo después de la décima segunda semana de gestación, -lo que implicaba la despenalización del aborto para quienes lo efectuaran antes de ese término-, haciendo la mención específica que para los efectos del Código, el embarazo es la parte del proceso de la reproducción humana que comienza con la implantación del embrión en el endometrio , y que además regula la sanción a la mujer que voluntariamente practique su aborto o consienta en que otro la haga abortar, después de las doce semanas de embarazo, enfatizando que en este caso, el delito de aborto sólo se sancionará cuando se haya consumado ${ }^{10}$.

- La inconstitucionalidad de la adición de los artículos 16 Bis 6, tercer párrafo y 16 Bis 8, último párrafo, de la Ley de Salud para el Distrito Federal, mismos que señalaban que las instituciones públicas de salud del gobierno del Distrito Federal atenderán las solicitudes de interrupción del embarazo a las mujeres solicitantes aun cuando cuenten con algún otro servicio de salud público o privado y que el gobierno del Distrito Federal otorgará servicios de consejería médica y social en materia de la atención a la salud sexual y reproductiva, funcionando de manera permanente con servicios gratuitos que ofrecerán la información, difusión y orientación en la materia, así como el suministro de todos aquellos métodos anticonceptivos cuya eficacia y seguridad estén acreditadas científicamente. Asimismo, proporcionarán a la mujer que solicite la interrupción de su embarazo la información a que se refiere el último párrafo del artículo 148 del Código Penal para el Distrito Federal. Los servicios de consejería también ofrecerán apoyo médico a la mujer que decida practicarse la interrupción del embarazo después del procedimiento de abor-

\footnotetext{
${ }^{9}$ Artículo 144 del Código Penal del ese entonces Distrito Federal (CPDF).

${ }^{10}$ Artículo 145 del CPDF
} 
to, particularmente en materia de planificación familiar y anticoncepción. - El Procurador General de la República también solicitó la invalidez del artículo tercero transitorio del decreto de reformas y adiciones mencionado y el presidente de la Comisión Nacional de los Derechos Humanos solicitó que la invalidez de las normas impugnadas se hiciera extensiva al artículo 148 del Código Penal para el Distrito Federal que señalaba las excluyentes de responsabilidad penal en el delito de aborto.

Al ser admitidas en la Suprema Corte, se les denominaron Acciones de Inconstitucionalidad 146/2007 y su acumulada 147/2007 y el 28 de agosto de 2008, luego de más de 17 horas de sesiones públicas, el pleno de la Suprema Corte de Justicia de la Nación resolvió por mayoría de ocho votos que son constitucionales los artículos impugnados, estableciendo que se reconoce la validez de los artículos impugnados como inconstitucionales.

La decisión tomada sobre estas acciones de inconstitucionalidad son determinantes en el avance de los derechos sexuales y reproductivos de las mujeres y otros derechos, pues dentro de sus consideraciones señaló (SCJN, 2008):

- Que la idea de la Asamblea Legislativa del Distrito Federal al despenalizar el aborto [...]fue acabar con un problema de salud pública derivado de la práctica de abortos clandestinos, estimando que la despenalización del aborto permitirá que las mujeres interrumpan voluntariamente su embarazo en condiciones de higiene y seguridad; asimismo, garantizar un trato igualitario a las mujeres, en específico aquéllas de menores ingresos, así como reconocerles libertad en la determinación de la forma en la que quieren tener relaciones sexuales y su función reproductiva; reconocer que no debe existir la maternidad forzada y se debe permitir que la mujer pueda desarrollar su proyecto de vida en los términos que lo estime conveniente. Se justificó, asimismo, que el procedimiento para abortar se lleve a cabo dentro del período de doce semanas, puesto que es más seguro y recomendable en términos médicos. La interrupción del embarazo se despenaliza únicamente para el período embrionario y no el fetal, antes de que se desarrollen las facultades sensoriales y cognitivas del producto de la concepción. La no penalización de la interrupción del embarazo tiene como contraparte la libertad de las mujeres para que decidan respecto de su cuerpo, de su salud física y mental e, incluso, respecto de su vida" y que "... el legislador tomó en cuenta que constituye una realidad social que las mujeres, que no quieren ser madres, recurran a la práctica de interrupciones de embarazos clandestinos con el consiguiente detrimento para su salud e incluso, con la posibilidad de perder sus vidas. (pág. 182).

- Que la Constitución no reconoce un derecho a la vida en sentido normativo, sino que [...]establece que una vez dada la condición de vida, existe una obligación positiva para el Estado de promocionarla y desarrollar condiciones para que todos los individuos sujetos a las normas de la Constitución aumenten su nivel de disfrute y se les procure lo materialmente necesario para ello "; de igual manera aseguró que no existe "...ningún fundamento constitucional o internacional para un mandato de penalización de su afecta- 
ción que permitiera sostener que existe una obligación del legislador para el establecimiento o mantenimiento de un tipo penal específico (pág. 175).

- Que [...en el lenguaje común y el lenguaje técnico de disciplinas como la medicina o la biología, el concepto de persona o de ser humano no incluye al producto de la concepción porque éste no es un individuo hasta que tiene la posibilidad de existir por sí solo, lo que no ocurre en las primeras doce semanas de gestación, por lo que ni el embrión ni el feto pueden ser titulares del derecho a la vida."] (pág. 56).

- Establece que incluso considerando que el producto de la concepción es persona titular de derechos, entre el derecho a la vida del embrión y los derechos de la mujer, prevalecen los de ésta por tratarse de una persona nacida y desarrollada, en pleno goce de sus capacidades, mientras que el embrión es sólo un potencial ser humano, que no es inviable pero sí incapaz de realizar funciones biológicas y cognitivas. Además, se trata de un solo derecho del embrión, el de la vida, frente a muchos derechos de la mujer, a la vida, la salud, la libertad reproductiva, la autodeterminación de su cuerpo, la protección de pactos que priven su libertad, su derecho a la intimidad y a la vida privada. (pág. 58)

- La resolución profundiza en uno de los principales argumentos usados en contra de la decisión de la mujer sobre su cuerpo y su futuro, al tratar de ponderar el derecho del futuro padre sobre el producto, por encima de los de la mujer.

Al respecto expresa que el derecho a decidir libremente el número y espaciamiento de los hijos tutela también la decisión de no tener hijos, esto es, de procrear o no procrear, lo que constituye un derecho de la persona y no conjunto, por lo que no puede afirmarse la inconstitucionalidad de la reforma impugnada porque no prevea el consentimiento del varón para la interrupción del embarazo, ya que ello implicaría otorgarle un veto que pasaría sobre la libertad de la mujer y permitiría que fuera el varón quien decidiera en definitiva al respecto. En todo caso, ante el conflicto de derechos que se presenta entre el derecho de procreación del padre que se opone a la interrupción del embarazo y el de la mujer para decidir libremente sobre el número y espaciamiento de los hijos, debe prevalecer el derecho de ésta pues ello no afecta permanentemente el derecho de procreación del varón y, por el contrario, de obligarse a la mujer a ser madre se altera su vida y su condición jurídica en forma permanente, además de afectarse sus derechos a la vida, la salud, a la autodeterminación de su cuerpo, a la libertad, la intimidad y la vida privada, máxime si se considera que se haría nugatorio totalmente el derecho de la mujer cuando el varón se encontrara ausente, o bien, ante la dificultad de la prueba de la filiación. (SCJN, 2008, págs. 62-63) 


\title{
CONTROVERSIA CONSTITUCIONAL 54/2009, “PÍLDORA DEL DÍA SIGUIENTE EN JALISCO” (SCJN, 2010)
}

\begin{abstract}
A través de esta controversia, promovida por el entonces Gobernador de Jalisco, Emilio González Márquez, se sometió al Pleno de la Suprema Corte de Justicia de la Nación determinar si es válida la modificación a la "Norma Oficial Mexicana NOM-190-SSA1-1999, Prestación de servicios de salud. Criterios para la atención médica de la violencia Familiar", para quedar como "NOM-046-SSA2-2005. Violencia familiar, sexual y contra las mujeres. Criterios para la prevención y atención”, publicada en el Diario Oficial de la Federación el 16 de abril de 2009.
\end{abstract}

En el contenido de la resolución, se desarrollaron los siguientes argumentos:

- Que en la vía de controversia constitucional no procede analizar los argumentos de los conceptos de invalidez sintetizados, pues de hacerlo se desnaturalizaría el sistema procesal de ese medio de control constitucional, el cual, principalmente, está dirigido a preservar las competencias de cada orden de gobierno previstas en la Constitución Política de los Estados Unidos Mexicanos. En consecuencia, los conceptos referidos resultan infundados. (pág. 55). - La fracción XVI del artículo 73 de la Constitución Federal confiere facultades al Congreso de la Unión para legislar en materia de salubridad general en toda la República. La salubridad general es una materia concurrente y la distribución de competencias entre la Federación y los Estados la estableció el Congreso de la Unión en la Ley General de Salud; misma que en su artículo 13 apartado A, fracción I, establece que corresponde al Ejecutivo Federal dictar las normas oficiales mexicanas en materia de salubridad general. En este sentido, no es óbice que las cuestiones relativas a la atención materna infantil y de planificación familiar sean competencia de las entidades federativas. Sin embargo, esta competencia se limita a la organización, operación, supervisión y evaluación de dichos servicios, lo que debe realizarse en los términos de las disposiciones aplicables -entre las que se encuentran las Normas Oficiales Mexicanas-. (pág. 13)

- Lo establecido para las víctimas en el ámbito constitucional, en particular el artículo 20, B, fracciones III y V, son deberes para las autoridades de procuración de justicia; no la concesión de exclusividad para su aplicación. Este deber genera un derecho para las víctimas: una garantía para la satisfacción inmediata del mismo, y no una limitación para que este derecho pueda ser exclusivamente garantizado por una sola autoridad, que además no es la que materialmente cuenta con la capacidad, conocimiento, especialidad para su eficaz tratamiento y prevención, como sí lo es el personal adscrito al Sistema Nacional de Salud. (pág. 63)

- La norma impugnada no vulnera el principio de igualdad y de no discriminación a que alude el accionante, pues si bien establece que las instituciones públicas de atención médica deberán contar con médicos y enfermeras capacitados en procedimientos de aborto médico no objetores de conciencia, 
ello no implica que exista desigualdad alguna entre objetores y no objetores de conciencia, pues la norma en ninguno de sus puntos establece que se deberá preferir a personal no objetor de conciencia respecto de quienes sí lo son. (pág. 43)

De esta manera, quedo clara la facultad concurrente en materia de salud entre los distintos niveles de gobierno y, sobre todo, la imposibilidad de las entidades federativas de querer imponer la maternidad a las mujeres que habían sido víctimas de violación, amparándose en su autonomía y/o soberanía y más bien, se aclara la obligación de éstas de someterse a las normas oficiales mexicanas expedidas en beneficio de los derechos de las personas.

\section{3) AMPARO EN REVISIÓN 601/2017. CASO MARIMAR}

El amparo en revisión señalaba la negativa a la Interrupción Legal del Embarazo (ILE) como tratos crueles e inhumanos equiparables a tortura, al negarle el servicio médico de interrupción del embarazo producto de una violación sexual a una menor de edad, además de que se había diagnosticado que el producto representaba un riesgo alto para la adolescente.

El personal del Hospital General de Cuernavaca, Morelos le negó la ILE a pesar de haber interpuesto la denuncia penal y en un "Acta de Reunión de Trabajo del Comité de Bioética”, se expuso que después de analizar el caso clínico de la paciente, no existía justificación alguna para la interrupción de su embarazo (SCJN, 2017, pág. 7), sin precisar las razones para justificar esa decisión, esto es, no expresó pormenorizadamente las circunstancias especiales, razones particulares o causas inmediatas que se hayan tenido en consideración para su emisión (pág. 8).

En el contenido de la resolución, existen diversos apartados en los que la Suprema Corte señala como tortura (y tratos crueles e inhumanos equiparables a aquella), la negativa del Estado -a través de sus servidores y funcionarios públicos- a proporcionar el servicio de ILE. Dichos apartados se señalan a continuación: (SCJN, 2017)

- Resalta que el Comité contra la Tortura de la Organización de las Naciones Unidas, al redactar el Informe CAT/C/CR/32/5, de catorce de junio de dos mil cuatro, sobre la situación de Chile, recomendó, entre otras cuestiones, lo siguiente (pág. 68):

- Eliminar la práctica de extraer confesiones a efectos de enjuiciar a las mujeres que buscan atención médica de urgencia como resultado de abortos clandestinos.

- De conformidad con las directivas de la Organización Mundial de la Salud, el Estado debe garantizar el tratamiento inmediato y sin condiciones de las personas que busca atención médica de emergencia. 
- Igualmente, el Comité externó su preocupación de que se condicione la atención médica a las mujeres cuya vida está en peligro por las complicaciones de abortos clandestinos.

- Remarca la obligación internacional de crear un marco jurídico suficiente que evite los abortos clandestinos en beneficio de los derechos a la vida, dignidad, derechos reproductivos y salud de la mujer y, en ese mismo orden, se erradiquen en los sistemas nacionales, toda vía que implique, criminalizar y, como consecuencia, discriminar a las mujeres que soliciten la interrupción del embarazo, se precisa que la negativa a la práctica de un procedimiento de aborto sí puede, bajo casos específicos, derivar en violación grave de derechos humanos, por implicar actos de tortura (pág. 68).

- Establece que no es posible que la autoridad desconozca su obligación so pretexto de una objeción de conciencia ${ }^{11}$, puesto que si bien un servidor público puede excepcionarse al cumplimiento de un mandato alegando objeciones personales irreconciliables, cierto es también que no puede tal circunstancia derivar en una violación irreparable de derechos humanos respecto de persona ajena y, por tanto, el servidor que objete en esos términos, debe buscar, encontrar, y ejecutar una medida alterna necesaria que garantice la concreción de la exigencia jurídica. (pág. 80)

Este caso tuvo el acompañamiento del equipo jurídico del Grupo de Información en Reproducción Elegida A.C. y gracias a ello se estableció este precedente y se otorgó el amparo de la Justicia Federal a Marimar, sin embargo, son muchos los casos en los que -independientemente de si la gestación del producto implica un riesgo para la vida de la mujer- los hospitales públicos se niegan a practicar la Interrupción Voluntaria del Embarazo (IVE) en casos de violación, desconociendo que dicha conducta se equipara a una tortura y es causa de responsabilidad.

\section{4) CASO FERNANDA. AMPARO EN REVISIÓN 1170/2017}

Los antecedentes del caso son los siguientes (SCJN, Crónicas del Pleno y de las Salas, 2018, pág. 2):

- En octubre de 2016, una mujer solicitó al Titular de la Dirección de Atención Médica de Servicios de Salud de la Secretaría de Salud del Estado de Oaxaca, la interrupción del embarazo producto de una violación sexual, hecho delictivo que fue denunciado ante la Agencia del Ministerio Público de la Fiscalía Especializada en Delitos contra la Mujer por razón de Género.

\footnotetext{
${ }^{11}$ La objeción de conciencia se define como "el derecho a oponer excepciones al cumplimiento de deberes jurídicos cuando su cumplimiento implique una contravención de las convicciones personales ya sean religiosas, morales o filosóficas", es decir, constituye una "negativa a someterse, por razones de conciencia, a un mandato jurídico que prescribe una conducta obligatoria y exigible, provenga el mandato de una norma legislativa, de un contrato, de una orden judicial o resolución administrativa." (RAE, 2016, pág. 1119).
} 
- Derivado de lo anterior, el Director de Atención Médica remitió dicha solicitud a la Directora de una institución de salud en el Estado de Oaxaca, a fin de que se le brindara a la interesada la atención médica oportuna.

- Una vez que fue informada de lo anterior, la mujer se presentó en las instalaciones de la institución médica a la que fue canalizada, sin embargo, ahí se le indicó que la referida institución se encontraba en paro laboral por el Sindicato de Trabajadores de la Secretaría de Salud, por lo que sólo atendían situaciones de emergencia.

- Inconforme, la mujer embarazada promovió juicio de amparo señalando, en esencia, que la negativa de aborto se constituía como tratos crueles e inhumanos equiparables a tortura, por lo que pedía se le reconociera su calidad de víctima al existir una violación grave a sus derechos humanos.

- Seguidos los trámites procesales, el Juzgado de Distrito al que le correspondió conocer del asunto, dictó sentencia en la que determinó, entre otras cuestiones, sobreseer en el juicio, al estimar que se actualizaba una causal de improcedencia, dado que la quejosa había informado bajo protesta de decir verdad, que el embarazo fue interrumpido mediante una intervención efectuada en un diverso hospital, por lo que entonces el asunto había quedado sin objeto o materia.

- En desacuerdo, la parte quejosa interpuso recurso de revisión del cual conoció un Tribunal Colegiado de Circuito, quien determinó que lo procedente era solicitar a la Suprema Corte de Justicia de la Nación que ejerciera su facultad de atracción para conocer del asunto.

La resolución, nuevamente señaló argumentos a favor de los derechos humanos de las mujeres frente a la intención de los agentes del Estado de vulnerar su derecho a decidir sobre sus cuerpos, primero al señalar que obligarla a seguir con un embarazo, implica tortura o tratos crueles y degradantes y por otra parte, que precisamente la IVE es un caso de urgencia, por lo que ante una incapacidad para brindar el servicio, debe verificarse que éste se proporcione efectivamente a la mujer, verificando que los derechos humanos de ésta no se vean afectados.

Entre los principales argumentos desarrollados están los siguientes: (SCJN, Amparo en revisión 1170/2017, 2018)

- La negativa del aborto (sin causa justificada) respecto de un producto derivado de una violación sexual, cuando tal interrupción es permisible en términos de la legislación penal aplicable, y cuya atención debe considerarse como de urgencia, se constituye como un acto violatorio grave de derechos humanos, que implica en sí mismo generar la continuidad en el daño ocasionado a la víctima, obligándola a llegar a término del embarazo (págs. 27-28).

- No puede aducirse como excusa a la atención médica de estos casos de urgencia, la paralización por huelga de los trabajadores sindicalizados de la Secretaría de Salud del Estado de Oaxaca, en virtud de que, como políticas de salubridad, debe existir atención a casos de urgencia como el presente y, cuando exista una imposibilidad material, suficientemente justificada, la institución médica debe ejercer sus recursos y facultades para procurar que 
diversa institución sanitaria atienda en calidad de emergencia la solicitud de mérito, siendo responsable del seguimiento cabal al procedimiento y conclusión efectiva de éste (págs. 23-24).

\section{5) AMPARO EN REVISIÓN 1388/2015}

Otro caso emblemático en el avance para comprender que los derechos humanos deben protegerse y garantizarse aplicando el control convencional, el principio de interpretación conforme y sobre todo el principio pro persona es el caso de Marisa, quien a través del amparo en revisión que interpuso y que fue resuelto por la Primera Sala de la Suprema Corte de Justicia de la Nación, logro que se estableciera que las autoridades deben ponderar los derechos de la mujer por encima de las de un producto en gestación, a pesar incluso de las limitaciones que existan en otros cuerpos normativos.

Los antecedentes del caso son los siguientes: (SCJN, Amparo en Revisión 1388/2015, 2019, págs. 1-3)

- El 24 de septiembre de 2013, la señora fue informada de que estaba embarazada por personal del Centro Médico Nacional, ubicado en la Ciudad de México; A su vez, los doctores que la atendieron le hicieron saber que su embarazo era considerado de alto riesgo pues, meses antes, se había sometido a una cirugía de bypass gástrico, tenía 41 años de edad y presentaba un problema de sobrepeso;

- Posteriormente, cuando tenía 15.5 semanas de gestación, se sometió a una prueba de amniocentesis genética con el objetivo de saber si el feto presentaba algún problema hereditario; El 30 de octubre de 2013, recibió los resultados de la amniocentesis genética, los cuales advertían que el feto de masculino presentaba síndrome de Klinefelter. Éste causaría que el feto no pudiera desarrollar sus genitales en la pubertad, pero no impediría que fuera una persona autosuficiente.

- Dadas todas estas complicaciones que ocasionan un riesgo a su salud física y emocional, Marisa solicitó verbalmente a los médicos del hospital que interrumpieran el embarazo un par de ocasiones; el 6 de noviembre de 2013, solicitó por escrito la interrupción de su embarazo, en ejercicio de su derecho a la salud y atendiendo a las características de alto riesgo de su embarazo, el cual ponía en riesgo su salud y vida -por su edad y sobrepeso.

- Al respecto -entre otros documentos- la señora anexó la opinión técnica de médico cirujano con especialidad en ginecología y obstetricia. En dicha opinión, el doctor detalló que la señora cursaba un embarazo de alto riesgo, por obesidad grado III, lo que le ocasionaba un riesgo materno mayor de diabetes, tromboembolismo y preeclampsia. A su vez, debido a la cirugía de bypass gástrico, precisó que la señora enfrentaba el riesgo de sufrir malnutrición y la obstrucción del intestino delgado por hernia interna. El emisor de la opinión médica recomendó la interrupción del embarazo. 
- Marisa se practicó el aborto en un hospital privado. Finalmente, el 20 de noviembre de 2013, recibió, por correo, la respuesta de las autoridades responsables de fecha 7 de noviembre de 2013. En ésta, se negaba su petición en razón de que el feto podría ser autosuficiente aunque tuviera síndrome de Klinefelter.

En específico, la autoridad respondió que la interrupción del embarazo, con base en la causal de salud, no era aplicable porque las leyes que rigen al ISSSTE no consideran los riesgos para la salud de la madre como causa suficiente. Por el contrario, consideraron que esta causal está relacionada con el feto, al señalar que el síndrome de Klinefelter que le fue detectado a aquél no es incompatible con la vida (SCJN, 2019, pág. 9).

Fue hasta el mes de mayo de 2019, que la Primera Sala resolvió el fondo del asunto, señalando que: (SCJN, Amparo en Revisión 1388/2015, 2019)

- Un aborto por razones de salud tiene como finalidad esencial restaurar y proteger la salud de la persona embarazada. Una salud que está siendo afectada no sólo por el embarazo, sino por el padecimiento físico o mental que aparece o empeora con su continuación; susceptible, además, de complicar el desarrollo del embarazo. De manera que la interrupción de embarazo provocada por una complicación de salud es el inicio de un proceso de recuperación de la salud y no su culminación, lo que hace crítica y presumiblemente violatoria de derechos humanos cualquier denegación o dilación deliberada de los servicios de atención médica destinados a resolver esos padecimientos (pág. 33).

- Entonces y dado que la salud es un derecho que protege tanto aspectos físicos como emocionales e, incluso, sociales, su adecuada garantía implica la adopción de medidas para que la interrupción de embarazo sea posible, disponible, segura y accesible cuando la continuación del embarazo ponga en riesgo la salud de las mujeres en su sentido más amplio. Esto implica que las instituciones públicas de salud deben proveer y facilitar esos servicios, así como abstenerse de impedir u obstaculizar el acceso oportuno a ellos.

La salud entendida en términos amplios supone una comprensión adecuada de los conceptos de bienestar y proyecto de vida. Desde esta perspectiva, el derecho a la salud es interdependiente de los derechos a la vida, a dignidad, a la autonomía, a la libertad, al libre desarrollo de la personalidad, a la información, a la no discriminación, a la igualdad, a la intimidad, a la privacidad y del derecho a estar libre de tratos crueles, inhumanos o degradantes. (pág. 52). - Cuando las mujeres solicitan servicios específicos que sólo ellas requieren, como la interrupción del embarazo por motivos de salud, la negación de dichos servicios y las barreras que restringen o limitan su acceso, constituyen actos de discriminación y una violación al derecho a la igualdad ante la ley. El vínculo entre los derechos a la libertad, la autonomía y el libre desarrollo de la personalidad y el derecho a la salud se concreta, por tanto, en los derechos a tomar decisiones sobre la propia salud y sobre el propio cuerpo (pág. 54).

- La relación específica entre salud, bienestar e interrupción del embarazo 
reconoce la posibilidad de acceder a una interrupción de embarazo, que sea segura, como una circunstancia que contribuye al bienestar de las mujeres, no sólo en aquellos casos en los que su integridad física se encuentre en riesgo, sino también cuando la continuación del embarazo se presenta como incompatible con su proyecto de vida (pág. 58).

- Corresponde al Estado, mediante las instituciones públicas de salud, garantizar el acceso oportuno a estos servicios cuando las mujeres enfrenten riesgos asociados con el embarazo que comprometan su salud física, mental o social, como parte del derecho a disfrutar de toda una gama de facilidades, bienes, servicios y condiciones necesarios para alcanzar el más alto nivel posible de salud, lo que abarca un sistema de salud que garantice que sean detectadas y atendidas diligentemente las circunstancias y padecimientos que comprometen ese bienestar (pág. 60).

\section{LA ALERTA DE VIOLENCIA DE GÉNERO POR AGRAVIO EQUIPARADO}

En México, en febrero de 2007 se publicó la Ley General de Acceso a las Mujeres a una Vida de Violencia, cuyo artículo $8^{\circ}$ regula la violencia institucional como una de las modalidades, señalando que: Son los actos u omisiones de las y los servidores públicos de cualquier orden de gobierno que discriminen o tengan como fin dilatar, obstaculizar o impedir el goce y ejercicio de los derechos humanos de las mujeres así como su acceso al disfrute de políticas públicas destinadas a prevenir, atender, investigar, sancionar y erradicar los diferentes tipos de violencia (LGAMVLV).

De igual manera, el Reglamento de la Ley General de Acceso a las Mujeres a una vida libre de violencia en su artículo 31, describe la hipótesis de la violencia de género por agravio comparado, al señalar que (RLGAMVLV, 2008):

La declaratoria de alerta de violencia de género por agravio comparado tendrá como finalidad eliminar las desigualdades producidas por un ordenamiento jurídico o políticas públicas que impidan el reconocimiento o el ejercicio pleno de los Derechos Humanos de las Mujeres protegidos en todos aquellos instrumentos internacionales reconocidos y ratificados por el Estado mexicano, a través de acciones gubernamentales previstas en el artículo 23 de la Ley.

El agravio comparado se presenta cuando un ordenamiento jurídico vigente o una política pública, contenga alguno de los siguientes supuestos y éstos transgredan los Derechos Humanos de las Mujeres:

I. Distinciones, restricciones o derechos específicos diversos para una misma problemática o delito, en detrimento de las mujeres de esa entidad federativa o municipio;

II. No se proporcione el mismo trato jurídico en igualdad de circunstancias, generando una discriminación y consecuente agravio, o

III. Se genere una aplicación desigual de la ley, lesionándose los Derechos Hu- 
manos de las Mujeres, así como los principios de igualdad y no discriminación.

$\mathrm{Al}$ existir una legislación en la Ciudad de México (CDMX) en la que no se sanciona la interrupción del embarazo cuando ésta se practica hasta antes de la décimo segunda semana y además el servicio se proporciona de manera gratuita y segura en clínicas del sector público de salud por así regularse en la ley de la materia vigente, queda evidenciada una distinción en la protección de un derecho específico como lo son los derechos sexuales y reproductivos de las mujeres de la Ciudad de México, respecto a las de las demás entidades; primero porque el delito del aborto se regula de manera diversa, lo que redunda claramente en que no se proporciona el mismo trato jurídico en igualdad de circunstancias a todas ${ }^{12}$, generando la idea de la existencia de privilegios para unas respecto a otras, lo que específicamente implica una discriminación que genera y sigue generando agravios, puesto que hay mujeres de otras entidades que por la cercanía que tienen con la Ciudad de México, por los recursos económicos con los que cuentan o por los apoyos, ayudas o acompañamientos que algunas asociaciones, organizaciones o colectivos pueden proporcionarles, logran trasladarse y efectuar la Interrupción Legal del Embarazo (ILE) en clínicas de la Ciudad de México sin ninguna criminalización o sanción legal.

Sin embargo, para el resto de las mujeres, las que no reciben educación sexual, no tienen información sobre opciones para efectuarse la ILE, las que son de escasos recursos y no pueden trasladarse, las que no conocen organizaciones o colectivos feministas que las asesoren y acompañen; para ellas esta aplicación desigual de la ley generada inicialmente por el simple hecho de haber nacido en una entidad distinta a la CDMX o Oaxaca, implica una desventaja que termina por lesionar sus derechos humanos, evidenciando violaciones a los principios de igualdad y no discriminación a los que se supone todas las leyes deberían estar alineadas.

Con esa seguridad, a petición de la organización civil "Equifonía: Colectivo por la ciudadanía, autonomía y libertad de las Mujeres”, en diciembre del 2017 el Estado de Veracruz se convirtió en la primera entidad de la República Mexicana en acumular dos Alertas de Violencia de Género contra las Mujeres (AVGM), una por violencia feminicida y la segunda, por tener un marco normativo que contraviene y violenta los derechos de las mujeres, en específico los sexuales, reproductivos y de salud, lo que llevó al INMUJERES y la CONAVIM a decretar el 13 de diciembre de 2017, la AVGM por “agravio comparado" (INMUJERES, 2017).

En virtud de la alerta, se emitieron medidas específicas al Poder Legislativo del Estado de Veracruz, en el sentido de armonizar su legislación penal para que sea considerado aborto a la interrupción del embarazo posterior a la décima segunda semana de gestación y que se consideren las excluyentes de aborto por violación, inseminación no consentida, riesgo de la salud, acción involuntaria y riesgos y factores externos incluyendo reformar la constitución del Estado y alinearla a la Ley de

\footnotetext{
${ }^{12}$ Incluso en Oaxaca, en donde únicamente se despenalizó pero no se aseguró la prestación del servicio de manera segura y gratuita por parte del estado, sigue habiendo la distinción en la regulación o atención de la problemática.
} 
Acceso a las Mujeres a una vida libre de violencia en Veracruz, en plazo no mayor a dos años, situación a la que hasta el momento, no se le ha dado cumplimiento.

Entre las medidas solicitadas, destacan: (CONAVIM, 2017)

Realizar la modificación del artículo 149 del Código Penal para el Estado Libre y Soberano de Veracruz de Ignacio de la Llave, conforme a lo establecido en el Informe del Grupo de Trabajo; reformar los artículos 150 y 154 del Código Penal para el Estado Libre y Soberano de Veracruz de Ignacio de la Llave; y divulgar e implementar la Ley General de Víctimas, la Ley de Víctimas para el Estado de Veracruz y la NOM 046 para la adecuada y diligente atención a víctimas de violencia sexual, garantizando el acceso a la interrupción legal del embarazo (ILE) por violación.

Igualmente, se deberá garantizar que en todas las regiones del Estado se cuenten con centros de salud en que se provean los servicios seguros, oportunos, de calidad y gratuitos para la ILE, y que, en caso de no contar con los mismos, se asegure su canalización a aquellos en los que se presta el servicio; y deberá contar con personal de salud no objetor de conciencia, capacitado en los métodos de interrupción legal del embarazo, tanto médicos como quirúrgicos.

Otras medidas son registrar los abortos médicos llevados a cabo por tipo de causal legal; llevar un efectivo control de constitucionalidad y convencionalidad, a través de la aplicación de los principios de interpretación conforme y pro persona, en los casos relacionados con el delito de aborto, y garantizar la reparación integral del daño para las víctimas de violaciones a derechos humanos por la falta de acceso al aborto legal.

También se señalan medidas a la Secretaría de Salud y a la Fiscalía General de Justicia del Estado de Veracruz para: a) Divulgar e implementar La Ley General de Víctimas, La Ley de Víctimas para el Estado de Veracruz y la NOM 046 para la adecuada y diligente atención de víctimas, y acceso garantizado a la ILE, b) Elaborar un programa Estatal de ILE, para garantizar el servicio sin dilación desde una perspectiva de salud integral y con los estándares requeridos a nivel nacional e internacional de los derechos humanos en la materia. c) Generar esquemas de difusión con confidencialidad y confianza para que las mujeres accedan al ILE sin necesidad de denuncia previa. (CONAVIM-INMUJERES).

Este precedente, amparado en la Ley General de Acceso a las Mujeres a una Vida Libre de Violencia y su reglamento, deja claro que en todas las demás entidades de la República en las que no se garantiza por parte del estado, sus instituciones y órganos, la práctica de la Interrupción del Embarazo en condiciones seguras, gratuitas y sin criminalización o sanción penal, se están flagrantemente violentando derechos humanos de las mujeres, lo que encuadra en violencia de género por agravio comparado. 


\section{REFLEXIONES FINALES}

Los derechos sexuales y reproductivos son una extensión del derecho a la salud, el cual no solo implica que la persona esté sana, sino también que es dueña de su salud y puede tomar decisiones sobre su cuerpo, su proyecto de vida, su bienestar, tener acceso a información y a servicios de salud sexual y reproductiva, sin ser objeto de violencia y discriminación por ningún agente del estado.

Penalizar el aborto es un acto de discriminación y violencia hacia las mujeres ejercido por el Estado mismo, según ha sido señalado por diversos instrumentos internacionales y los Comités de Seguimiento de los mismos que se han instalado y que permanentemente sesionan emitiendo recomendaciones a los estados parte, entre ellos México, a fin de eliminar los obstáculos legales que criminalizan a las mujeres que abortan, sobre todo cuando en dos entidades federativas -Ciudad de México y Oaxaca- ya se encuentra despenalizado hasta la décima segunda semana, mientras que en los demás estados únicamente se contemplan determinadas causales que siguen limitando el derecho a decidir.

La interrupción del embarazo es una decisión de la mujer gestante y debe respetarse sin criminalización, pues es parte de sus derechos sexuales y reproductivos y se relaciona con el ejercicio de muchos más derechos humanos, pero especialmente con el derecho al libre desarrollo de su personalidad, a la libertad, la autonomía, el derecho a la salud y al de decidir sobre sus cuerpos.

Existen ya diversos criterios a nivel internacional y de la Suprema Corte de Justicia de la Nación que han dejado clara la diferencia entre vida humana y persona humana, señalando que es a la mujer como persona humana a la que protegen los instrumentos normativos de todos los niveles por ser ésta la que es sujeta de derechos y que justo es esa persona la única que tiene derecho a decidir si quiere o no continuar con un embarazo por lo que no se puede ponderar el derecho de un hombre a ser padre, imponiendo la maternidad a la mujer, lo que alteraría su vida y su condición jurídica en forma permanente, además de afectarse sus derechos a la vida, la salud, a la autodeterminación de su cuerpo y a la libertad entre otros.

Al ser punible el aborto en la mayor parte del territorio mexicano, se configura violencia de género contra las mujeres por agravio comparado cometido por el Estado y específicamente por las y los legisladores de las entidades federativas en donde se criminaliza la interrupción del embarazo cuando éste se comete antes de la décimo segunda semana, puesto que las mujeres que viven o pueden trasladarse a la Ciudad de México o Oaxaca, tienen una regulación que no las criminaliza por tomar decisiones sobre sus proyectos de vida.

Con toda la argumentación lógica, jurídica y objetiva desarrollada, no hay razón para que el aborto siga siendo punible por lo menos hasta la décimo segunda semana de gestación en el resto de las entidades federativas. 
Es necesario que el Estado respete el derecho de las mujeres a decidir sobre sus cuerpos, y más bien se asegure de armonizar con perspectiva de género la legislación vigente y deje de replicar estereotipos que generan, discriminación y violación de derechos humanos de las mujeres.

El antecedente de la declaratoria de la Alerta de Violencia de Género contra las Mujeres por agravio comparado emitida para el Estado de Veracruz evidencia la violencia institucional que el estado, a través de sus órganos e instituciones cometen flagrantemente en contra de quienes representan a más de la mitad de la población en el Estado mexicano, contraviniendo los compromisos contraídos al suscribir diversos instrumentos internacionales de los que México es parte.

Las colectivas feministas en el país que reclaman se garanticen sus derechos sexuales y reproductivos y específicamente su derecho a la interrupción del embarazo de forma legal, segura y gratuita son cada vez más; el clamor social es cada vez más alto, firme, continuo y exige que el marco legal se adecue a la realidad social, al control convencional e incluso a los criterios que han sido emitidos por quién representa la cabeza del Poder Judicial de la Federación: La Suprema Corte de Justicia de la Nación.

La mujer gestante es la persona autónoma, la sujeta de derechos, la que debe tener la libertad de decidir si maternar o no, puesto que es ella la que tendrá que afrontar las consecuencias propias de la maternidad y las implicaciones en su proyecto de vida. Obligarla a continuar con la gestación es equiparable a la tortura, por tanto, el tema del aborto debe dejar de ser un estandarte político utilizado a conveniencia.

Las mujeres que deciden abortar son una realidad que el Estado se niega a aceptar; es esa realidad la que debe ser integrada en el texto legal de todas las entidades federativas del país, puesto que el derecho de las mujeres a decidir sobre sus cuerpos, al libre desarrollo de la personalidad, a la salud integral y a la dignidad, son derechos humanos y no son negociables, no deben estar sujetos a consulta; Son inherentes a las personas y deben garantizarse, protegerse, respetarse y fomentarse.

El derecho debe ajustarse a la realidad y al control convencional.

\section{REFERENCIAS}

1. ACNUDH. (2018). Oficina del Alto Comisionado de las Naciones Unidas para América el Sur. Ginebra 27 de septiembre de 2018. Obtenido de https://acnudh.org/expertosonu-en-derechos-humanos-los-estados-deben-actuar-ahora-para-permitir-abortos -seguros-y-legales-para-mujer

2. Adhanom Ghebreyesus, T. (10 de diciembre de 2017). Declaración del Director General de la OMS en el marco del Día de los Derechos Humanos 2017. La salud es un derecho humano fundamental. Obtenido de https://www.who.int/mediacentre/news /statements/fundamental-human-right/es/ 
3. Caba, E., \& Vázquez, M. (s.f.). Salud y Derechos Sexuales y Reproductivos en Cooperación Internacional. Guía metodológica. Documento elaborado por HYPATIA Consultoría para Paz y Desarrollo. Obtenido de http://www.pazydesarrollo.org/wp-content/uploads/2016/12/guia_derechos_sexuales_y_reproductivos.pdf

4. Caso Artavia Murillo y otros (“Fecundación In Vitro") Vs. Costa Rica., Sentencia de 28 de noviembre de 2012 (Excepciones Preliminares, Fondo, Reparaciones y Costas) (Corte Interamericana de Derechos Humanos). Obtenido de http://www.corteidh.or.cr /docs/cas

5. CEDAW. (02 de febrero de 1999). La mujer y la salud. Recomendación General 24. Obtenido de https://www.acnur.org/fileadmin/Documentos/BDL/2001/1280.pdf

6. CELS. (s.f.). Aborto legal, argumentos, legislación y jurisprudencia. Buenos Aires, Argentina: Centro de estudios legales y sociales (CELS). Edición de Vanina Escales. Obtenido de https://www.cels.org.ar/web/wp-content/uploads/2018/05/AbortoLegal.pdf

7. CONAVIM. (13 de Diciembre de 2017). Comisión Nacional para Prevenir y Erradicar la Violencia Contra las Mujeres. Obtenido de https://www.gob.mx/conavim/prensa/segob -declara-alerta-de-violencia-de-genero-contra-las-mujeres-por-agravio-comparado -para-el-estado-de-veracruz?idiom=es

8. CONAVIM-INMUJERES. (s.f.). Página Oficial del Gobierno del Estado de Veracruz. Obtenido de Alerta de Violencia de Género contra las Mujeres Veracruz: http://www.veracruz.gob.mx/wp-content/uploads/2019/02/5_Declaratoria-Veracruz-AC.pdf

9. CPDF. (s.f.). Código Penal para el Distrito Federal. CDMX, México. Obtenido de http: //www.paot.org.mx/centro/codigos/df/pdf/2019/COD_PENAL_DF_31_12_2018.pdf

10. CPOAX. (s.f.). Código Penal Oaxaca. Oaxaca. Obtenido de http://docs64.congresooaxaca.gob.mx/documents/legislacion_estatals/Codigo+Penal+para+el+Edo+ de+Oax+(Ref+dto+1502+aprob+LXIV+Legis+15+abr+2020+PO+Extra+17+abr+2020). pdf

11. DEC806. (24 de Octubre de 2019). Periódico Oficial del estado libre y soberano de Oaxaca. Decreto 806 mediante el cual se reforman, derogan y adicionan diversas disposiciones al Código Penal para el estado libre y soberano de Oaxaca. Oaxaca de Juárez. Obtenido de http://www.periodicooficial.oaxaca.gob.mx/files/2019/10/EXT-DECRETO 806-2019-10-24.pdf

12. DOF. (08 de diciembre de 1998). Diario Oficial de la Federación. DECRETO por el que se aprueba la Declaración para el reconocimiento de la competencia contenciosa de la Corte Interamericana de Derechos Humanos. Ciudad de México. Obtenido de http://dof.gob. $\mathrm{mx} /$ nota_detalle.php?codigo $=4902104 \&$ fecha $=08 / 12 / 1998$

13. Faundes, A. (2015). Malentendidos sobre el efecto de la legalización del aborto. Anales de la Facultad de Medicina, vol. 76, núm. 4, octubre-diciembre, 2015, 425-429. Obtenido de https://www.redalyc.org/pdf/379/37943429014.pdf 
14. INMUJERES. (13 de Diciembre de 2017). Instituto Nacional de las Mujeres. Obtenido de Gobierno de México. Acciones y Programas: https://www.gob.mx/inmujeres/acciones-y-programas/alerta-de-violencia-de-genero-contra-las-mujeres-80739

15. LGAMVLV, Ley General de Acceso a las Mujeres a una Vida Libre de Violencia. Obtenido de http://www.diputados.gob.mx/LeyesBiblio/pdf/LGAMVLV_130418.pdf

16. OHCHR. (s.f.). Observación general núm. 36 sobre el artículo 6 del Pacto Internacional de Derechos Civiles y Políticos, relativo al derecho a la vida. La Oficina del Alto Comisionado para los Derechos Humanos. Obtenido de https://www.ohchr.org/Documents/HRBodies/CCPR/GCArticle6/GCArticle6_SP.pdf

17. OMS. (s.f.). Página Oficial de la Organización Mundial de la Salud. Obtenido de http/www. oms.org

18. ONU. (4 al 15 de noviembre de 1995). Informe de la Cuarta Conferencia Mundial. Beiging. Obtenido de https://www.un.org/womenwatch/daw/beijing/pdf/Beijing\%20full\%20report\%20S.pdf

19. ONU. (s.f.). Informe de la Conferencia Internacional sobre Población y Desarrollo. 5 a 13 de septiembre de 1994. El Cairo: Organizacion de las Naciones Unidas. Obtenido de https://www.unfpa.org/sites/default/files/pub-pdf/icpd_spa.pdf

20. ONUMUJERES. (24 de Julio de 2018). Comité CEDAW emite observaciones a México sobre derechos de las mujeres luego de $9^{\mathrm{a}}$ revisión. Obtenido de https://mexico.unwomen.org/es/noticias-y-eventos/articulos/2018/07/comunicado-cedaw

21. RAE. (2016). Real Academia Española y Consejo General del Poder Judicial. Diccionario del Español Jurídico. España, Barcelona.: Espasa Libros.

22. RLGAMVLV. (11 de marzo de 2008). Reglamento de la Ley General de Acceso a las Mujeres a una Vida Libre de Violencia. Obtenido de http://www.diputados.gob.mx/LeyesBiblio/regley/Reg_LGAMVLV.pdf

23. SCJN. (28 de agosto de 2008). Tibunal Pleno de la Suprema Corte de Justicia de la Nación. Acción de inconstitucionalidad 146/2007 y su acumulada 147/2007. Ciudad de México. Obtenido de https://www.sitios.scjn.gob.mx/codhap/sites/default/files/engrosepdf_sentenciarelevante/DESPENALIZACION\%20ABORTO\%20DF\%20AI\%20146 -2007_0.pdf

24. SCJN. (2010). Acción de inconstitucionalidad 54/2009. Caso "La píldora del dia siguiente", Pleno de la Suprema Corte de Justicia de la Nación, Ciudad de México. Obtenido de http://www2.scjn.gob.mx/ConsultaTematica/PaginasPub/DetallePub.aspx?Asunto ID $=109935$ 
25. SCJN. (2017). Amparo en Revisión 601/2017. Segunda Sala de la Suprema Corte de Justicia de la Nación. Obtenido de https://www.scjn.gob.mx/sites/default/files/listas/documento_dos/2018-02/AR-601-2017.pdf

26. SCJN. (2018). Amparo en revisión 1170/2017. Segunda Sala de la Suprema Corte de Justicia de la Nación, Ciudad de México. Obtenido de https://www.law.utoronto.ca/utfl_file/count/documents/reprohealth/mexico_2018_rape_fernanda.pdf

27. SCJN. (2018). Crónicas del Pleno y de las Salas. La Interrupción legal del embarazo derivado de una violación sexual, debe ser atendido por las instituciones de salud como caso urgente. (J. A. Alemán, Recopilador) Ciudad de México. Obtenido de https://www.scjn.gob.mx/sites/default/files/sinopsis_asuntos_destacados/documento/2018-05/2S180418-JFFGS-1170.pdf

28. SCJN. (2019). Amparo en Revisión 1388/2015. Primera Sala de la Suprema Corte de Justicia de la Nación. Obtenido de https://www.scjn.gob.mx/sites/default/files/listas/documento_dos/2019-04/AR\%201388-2015\%20-\%20190404.pdf 